\title{
A Method of Determining Rail Grinding Parameters Based On Life-Cycle Cost
}

\author{
Wang Jianxi ${ }^{1,2, *}$, Chen Siyi ${ }^{3}$ and Gui Jirong ${ }^{1}$ \\ ${ }^{I}$ School of Civil Engineering, Shijiazhuang Tiedao University, Shijiazhuang, Hebei Province, 050043, P.R. China; ${ }^{2}$ Key \\ Laboratory of Road and Railway Engineering Safety Control of Ministry of Education, Hebei Province ,050043, P.R. \\ China; ${ }^{3}$ School of Transportation Engineering, Shijiazhuang Tiedao University, Shijiazhuang, Hebei Province, 050043, \\ P.R. China
}

\begin{abstract}
The factors affecting the economy efficiency of rail grinding and their interrelation are researched. Based on the management theory of life-cycle cost, the model of analyzing rail grinding parameters is established, the calculation method is determined, and minimizing the rail life-cycle cost is regarded as optimization objective for the optimal analysis of grinding factor. The results prove that with certain parameters (grinding interval and mental removal), the total present value of rail cost tends to decrease firstly and then increase with the increase of rail service life. With the increase of the grinding interval, the total present value of rail cost also tends to decrease firstly and then increase, and there is an extreme point in the variation tendency. In the economic cost of rail service life, rail replacement and waste of railway taking-up cost are two of the biggest parts. Therefore, reasonable rail maintenance strategy plays a significant role in reducing life-cycle cost.
\end{abstract}

Keywords: Railway Engineering, Rail, Rail Grinding, Life-Cycle Cost, Grinding Factor, Optimization.

\section{INTRODUCTION}

With the application of grinding, people learn more about the grinding effect and benefit, thus gradually regarding grinding as a routine maintenance measure instead of emergency repair [1]. However, we also find that frequent grinding significantly disturbed the railway transportation. With the mixed traffic of passenger and freight and heavy-haul railway in China, which have fast growing rail damage and high traffic density, the interference is even greater. Using rail grinding can prolong rail service life, improve track riding quality and economize the maintenance costs. However, it is also an expensive maintenance measure. It is a longterm behavior to apply maintenance (rail grinding) simultaneously for ensuring the running quality, rather than provisional measures. It becomes an urgent problem about how to arrange the maintenance (rail grinding) to obtain the most cost-effective measure, which can ensure the running quality as well as reduce the interference with normal transportation. Kalousek and Magel, Magel et al. [2,3] researched the wear condition of North American railway and proposed preventive rail grinding parameters (grinding interval and mental removal). Schoech Heyder, and Grohmann [4] continuously observed the growth of fatigue cracks and wear condition, and determined the measure of rail maintenance. Jin et al. [5] summarized the theory, the technology and presented a comprehensive economic model of rail maintenance cost which included depreciation expense of grinding equipment, based on the existing foreign model. Zhou, Tian and Zhang[6] suggested the rail grinding interval based on the profile of the running wheel and track of Chinese high-speed railway. Life-cycle cost management is a method of economic analysis. It is a management principle and method that minimizes

*Address correspondence to this author at Shijiazhuang Tiedao University, Shijiazhuang,Hebei,050043, P.R. China; Tel: +86 15930170825;

E-mail: qianxi-2008@163.com the life-cycle cost from the point of system optimization by proceeding from the long-term economic benefits, and fully considering the whole process from project, design, building, purchase, operation, maintenance, update and transformation of the instrument or system to the abandonment [7-9]. Compared with traditional economic analysis, life-cycle cost management focuses on the long-term profit, and is aimed at the minimum of the whole project life cost. Therefore, this article introduces life-cycle cost management into the rail grinding management and determines economy grinding interval and mental removal to make the rail grinding obtain the best cost-benefit ratio.

\section{FACTORS AFFECTING RAIL GRINDING ECO- NOMICAL EFFICIENCY}

\subsection{Mental removal, grinding interval and rail replace- ment cycle}

Viewed from rail intensity, grinding decreases the rail intensity. However, rail has to exhibit a definite range of intensity to ensure normal operation of route. Rail should be replaced when the rail intensity decreases to a certain degree, which is to say, reaching the wear limit. Excessive grinding (unnecessary removal of railhead material) may bring forward the rail replacement for the high wear rate. Thus, in this article, balancing the mental removal and actual grinding which is needed to control surface defect, fatigue and deterioration of profile, is considered to be very important, and the wear loss (including mental removal) and fatigue crack should be balanced in order to obtain the maximum rail service life.

Mental removal and rail replacement cycle are closely related. When the mental removal is larger than what needed to control surface defect and fatigue, the rail service life is restricted by wear limit; the greater the metal removal, the shorter the rail life, so the smaller the rail change interval. 
But if the mental removal is less than what needed to control surface defect and fatigue, the rail service life is restricted by fatigue; the smaller the metal removal, the more serious the rail surface damage, the shorter the fatigue life of rail, and the smaller the rail change interval. Whether it is optimum to replace rail, when fatigue life and wear life are equal? This depends on the factors of grinding effects and rail detection. If the effect of grinding is fine, and relevant supporting measures are well in place (e.g. Better lubrication will decrease rail wear, especially side wear), thus the rail service life and rail replacement cycle will be prolonged, and vice versa.

According to the thought of optimal wear rate, different grinding intervals lead to different mental removal, that is mental removal and grinding interval are closely related. Therefore, this paper argues that metal removal, grinding inter-val and rail change interval are closely related to each other, and should be analyzed as a whole in terms of rail life cycle cost.

\subsection{Productivity}

Modern rail grinding wagon has a great capacity of grinding. Rational utilization of the grinding capacity can improve productivity greatly and reduce the expense of each grinding section. Productivity is mainly affected by "skylight" time, grinding rate, grinding time availability and grinding strategy.

Grinding is usually operated in specified operating range during "skylight" time. As a result, the length of "skylight" may frequently affect productivity. If the "skylight" time is enough, the available time for grinding is long, and the proportion of nonworking time is little, so the productivity is high, vice versa. But it is hard for busy route to extend the "skylight" time.

Another factor affecting productivity is grinding rate. Modern grinding wagon has characteristics of high grinding rate and large mental removal. Using modern grinding wagon for preventive grinding can obtain high productivity and reduce grinding cost per unit length accordingly.

Grinding rate and grinding time availability are strongly affected by grinding type, including mental removal and the whole grinding strategy. Grinding strategy deals with the choice between removing damage grinding or preventive grinding, the selected grinding way and the type of target profile. The first case, removing damage grinding, is a traditional measure which allows the damage to grow to a certain depth. It needs a larger mental removal, which is usually operated in low velocity $(3 \mathrm{~km} / \mathrm{h} \sim 6 \mathrm{~km} / \mathrm{h})$ repeatedly. Thus it causes low productivity.

On the other hand, preventive grinding is based on frequent operation but less mental removal in high velocity. Grinding wagon can work in train intervals (it has appropriate time for grinding on the rails), so during the "skylight" time it will grind a large number of rails, obtaining the largest mental removal (according to the grinding mileage). Onetime preventive grinding at high velocity can achieve high productivity.

Besides, the choice of continuous grinding or selective grinding (such as only grinding curve rails) is also an im- portant factor affecting productivity. Grinding curve rails is always the primary task. Grinding straight rails can remove the corrugation and the other damage. Continuous grinding is used to grind straight rails in high velocity to reduce slight damage on the surface, and grind curve rails (if necessary) in low velocity with large mental removal. If only grinding curve rails, the running time between curves may affect the productivity.

\subsection{The Amount of Maintenance}

After grinding, wheel-rail relation is improved, incidence rate of damage is reduced, corresponding maintenance workload decreases (direct performance is the reduced workload of crack), and maintenance cost is also cut down. In the different grinding interval, that the grinding is operated in different degree of rail damage, due to the developing rail damage, the condition of heavy damage or rail breaking is different, so is the workload of corresponding emergency maintenance.

Rail service life is also extended after grinding. Along with the service time, the strength of rail and track structure decrease (both the rail grinding and nature wear remove the railhead metal materials), which cause deformation easily and create more extra work and cost of maintenance.

\section{THE THEORY OF ANALYTIC MODEL OF RAIL GRINDING PARAMETERS BASED ON LIFE-CYCLE COST}

\subsection{Model Assumptions}

Grinding parameters (mental removal and grinding interval) are bound up with rail service life, which are associated as an integral. Hence, in the economic analysis of grinding interval, rail service life should not be the time limit, and adequate time shall be offered instead. The analytic model of rail grinding parameters based on life-cycle cost is a mathematic model that takes into account the time value of fund, analyzes the rail cost in a long time according to the relation between grinding parameters and rail service life, and determines economy grinding parameters and rail service life by optimization analysis. The following assumptions are used in this model:

(1) Transportation mode remains the same.

(2) Grinding wagon has good reliability. During the grinding, the condition of downtime caused by mechanical failure would not be taken into account.

(3) Within certain limits, the grinding wagon can work successfully.

(4) "Skylight" time is enough for completing scheduled grinding tasks.

(5) In different grinding strategies, the distribution of rail damage is considered as the same.

(6) Rails are in good lubrication condition.

(7) The grinding is operated according to the grinding interval, without delay or forwardness.

(8) Annual cost arises at the beginning of the year. 


\subsection{Definition of Model Parameters}

The principal factors affecting the economy efficiency of rail grinding are grinding parameters, rail replacement cycle, productivity and maintenance amount. Hence, in the analytic model of rail grinding parameters based on life-cycle cost, rail cost includes rail grinding cost, rail replacement cost, emergency repair cost, crack detection cost, derailment cost,

railway taking-up cost and daily maintenance cost. The calculation of daily maintenance cost is mainly about the cost saved by decreased daily maintenance due to the optimized wheel rail relation, and the increased maintenance amount due to reduced intensity resulted by rail grinding and wears. However, these two kinds of expense cannot be determined well, so the daily maintenance cost is ignored. In circulation, monetary capital participates in the reproduction process as social production fund will be value-added and create new profits, called the time value of money [7]. Various costs are converted into present value based on the time value of fund so as to make comparative analysis of rail operation costs with different grinding parameters.

\subsubsection{Analysis of Rail Failure}

During its service, a variety of reasons cause rail failure. The condition of rail failure varies from stage to stage, and lots of scholars have done much research in rail failure distribution. Many studies have shown that Weibull distribution can describe rail failure well.

Weibull distribution $[10,11]$ describes the rail failure like this:

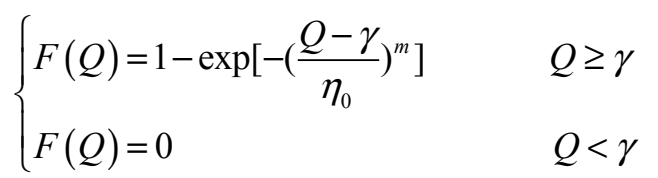

Where: $F(Q)$ is failure probability; $Q$ is passing gross load; $\gamma$ is location parameter, also known as minimum warranty life; $\eta_{0}$ is scale parameter; $m$ is shape parameter.

When the passing gross load is between $Q_{i}$ and $Q_{i+1}$, rail failure rate is $F N_{i i+1}$ :

$$
\begin{aligned}
F N_{i i+1} & =\int_{Q_{i}}^{Q_{i+1}} \frac{f(Q)}{1-F(Q)} d Q=\int_{Q_{i}}^{Q_{i+1}} \frac{F^{\prime}(Q)}{1-F(Q)} d Q \\
& =\int_{Q_{i}}^{Q_{i+1}} \frac{m}{\eta_{0}^{m}}(Q-\gamma)^{m-1} d Q=\frac{1}{\eta_{0}^{m}}\left[\left(Q_{i+1}-\gamma\right)^{m}-\left(Q_{i}-\gamma\right)^{m}\right]
\end{aligned}
$$

Where: $f(Q)$ is the probability density function of Weibull distribution, $f(Q)=F^{\prime}(Q)$, the other parameters are same as before.

\subsubsection{Rail Grinding Cost}

As a result of different grinding strategy, the rail mental removal is different, some rails need only once grinding, and the others need grinding again and again. The grinding cost shall be computed based on the times (mental removal) and the grinding length. In the $j$-th year, to the $L$ meters long rail, mental removal is $h_{G}^{k}$ (which needs $n_{G}^{k}$ times), present value of $t$ times grinding $\operatorname{cost}$ is $c_{G}^{j}$ :

$c_{G}^{j}=\frac{\left(\sum_{k=1}^{t} c_{G}^{\prime} \cdot n_{G}^{k} \cdot L\right)}{(1+r)^{j-1}}$

Where: $c_{G}^{\prime}$ is the cost of grinding wagon working once per meter; $r$ is discount rate.

\subsubsection{The Cost of Rail Replacement}

Replacing $L$ meters rail in $j$ years, the present value of the rail replacement $\operatorname{cost} c_{\mathrm{Re}}^{j}$ is:

$c_{\mathrm{Re}}^{j}=\frac{\left(c_{\mathrm{Re}}^{\prime} \cdot L\right)}{(1+r)^{j-1}}$

Where: $c_{\mathrm{Re}}^{\prime}$ is the unit price of rail replacement cost; the meaning of other parameters is same as before.

\subsubsection{The Cost of Emergency Repair}

According to the rule of maintenance [12], it should be processed in time when serious injured rail is found by flaw detection or broken rail is found by check. The cost of emergency repair here mainly refers to the cost of emergency repair and permanent solution of seriously damaged rail or broken rails.

Taking $t$ times emergency repair in $j$ years, the present value of the emergency repair $\operatorname{cost} c_{U}^{j}$ is:

$c_{U}^{j}=\frac{\left(c_{U}^{\prime} \bullet t\right)}{(1+r)^{j-1}}$

Where: $c_{U}^{\prime}$ is the unit price of emergency repair; the meaning of other parameters is same as before.

The times of emergency repair in $j$ years were determined by the result of rail flaw detection.

\subsubsection{The Cost of Flaw Detection}

Rail breakage (like fatigue crack) may result in rail break. Rail breakage is the important reason of derailment. Using rail flaw detection, that is a method with nondestructive testing, can detect the breakage which may result in rail fracture so as to eliminate the potential safety hazard. Taking $t$ times flaw detection for $L$ meters line in $j$ years, the present value of flaw detection $\operatorname{cost} c_{I}^{j}$ is:

$$
c_{I}^{j}=\frac{\left(c_{I}^{\prime} \cdot t \cdot L\right)}{(1+r)^{j-1}}
$$


Where: $c_{I}^{\prime}$ is the unit price of flaw detection; the meaning of other parameters is same as before.

\subsubsection{The Cost of Derailment Loss}

After rail grinding, the rate of rail breakage will decline. But rail breakage still exists, even rail breaking may occur. After rail flaw detection, some rail breakage may be found, and then measures are taken to prevent the accident. However, flaw detection can't detect all breakage. Thus, part of breakage on the line which is not probed may cause the derailment. In $j$ years, if $t$ times derailment occurred, the present cost of derailment loss $c_{D}^{j}$ is:

$c_{D}^{j}=\frac{\left(c_{d}^{\prime} \bullet t\right)}{(1+r)^{j-1}}$

Where: $c_{D}^{\prime}$ is the loss of one derailment; the meaning of other parameters is same as before.

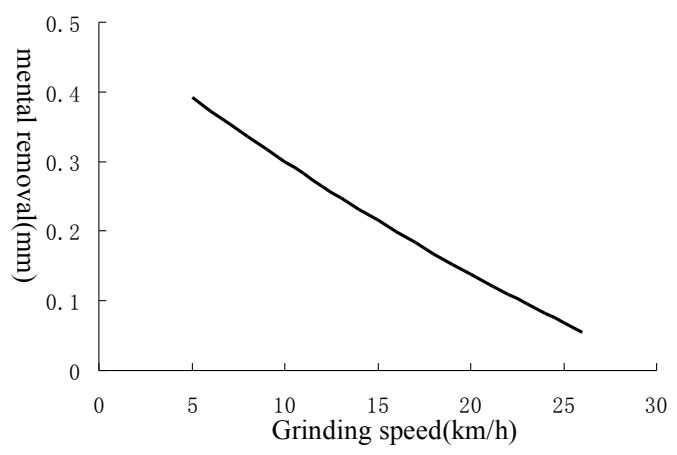

Fig. (1). The relationship between mental removal and speed.

\subsubsection{The Railway Taking-up Cost}

Grinding is operated in specified operating range in "skylight" time. So blocking the certain range of line is very necessary when taking rail grinding, and the normal transportation will be disrupted. Transportation disruption is a kind of loss for railway transportation. The loss of normal transport disruption caused by blocking line due to the rail grinding is called railway taking-up cost, which is directly related to the railway taking-up time. Taking-up time is directly proportional to the disturbance on transport and the railway taking-up cost. The railway taking-up time is determined by grinding assignment, grinding speed and grinding plan. Grinding plan determines the availability of "skylight" time. If the grinding plan is not very well, it will waste a lot of time on traveling to the designated operations areas or other non-grinding work, and the utilization rate of "skylight" time, which can be used to indicate the merits of grinding plan, is low. The bigger the mental removal, the longer the railway taking-up time it needs. At the analytic model of rail grinding parameters based on life cycle cost, "skylight" time is assumed long enough to assure scheduled grinding operation. Therefore, at the situation of enough "skylight" time (the utilization rate of "skylight" time is confirmed) the railway taking-up time is determined by grinding velocity.
The velocity of rail grinding wagon is called grinding speed, and it is one of the key dominant parameters to determine grinding type, grinding depth and grinding quality. When the grinding speed is beyond the ability of rail grinding wagon, it will cause phenomena such as different degree of rail surface finish, edge failure, poor rail surface finish, and nonuniform distribution of mental removal. But if the grinding speed is too low, it will cause the rail grinding surface defects including metallographic breakage ("fire burn") and rail surface groove. According to the literature [13], a relationship between mental removal and grinding speed is identified, as shown in Fig. (1).

The relationship between mental removal and rail grinding wagon speed is inverse function as shown in Fig. (1). Grinding speed can be determined by mental removal, and taking-up time can be determined based on "skylight" time availability. Taking $t$ times flaw detection on $L$ meter line with $h_{G}^{k}$ mental removal (the grinding speed is $V_{G}^{k}$ ) in $j$ years, the present value of $c_{L o}^{j}$ is:

$c_{L o}^{j}=\frac{\left(\sum_{k=1}^{t} \frac{c_{L o}^{\prime} \cdot L}{V_{G}^{k} \cdot U R}\right)}{(1+r)^{j-1}}$

Where: $U R$ means the availability of "skylight" time; $c_{L o}^{\prime}$ is the unit price of railway taking-up cost; the meaning of other parameters is same as before.

\subsection{Objective Function and Constraint Condition of Model}

Life cycle cost management refers to a management concept and method that minimizes life cycle cost from perspective of long-term economic benefits of the project, and take into account cost management in respect of system optimum. Therefore, at the analytic model of rail grinding parameters based on life cycle cost, optimization objective is to minimize the cost of rail in the life cycle. At the analysis model of rail grinding parameters based on life cycle cost, there are six model parameters: rail grinding cost, rail replacement cost, emergency repair cost, flaw detection cost, derailment cost and railway taking-up cost. These model parameters are also the function of grinding parameters (mental removal and grinding interval) and rail replacement cycle (the service life of rail). Accordingly, the objective function of life cycle cost based rail grinding parameters analysis model is:

$$
\begin{array}{ll}
\min & \sum_{j=1}^{N F}\left(c_{G}^{j}+c_{\mathrm{Re}}^{j}+c_{U}^{j}+c_{I}^{j}+c_{D}^{j}+c_{L o}^{j}\right) \\
\text { s.t. } & \mathrm{V}_{Q}^{w}+h_{G} / Q_{G}=h_{Q_{0}} / Q_{G} \\
& Q_{L e} \leq Q_{L e}^{w}
\end{array}
$$

Where:

$$
\sum_{j=1}^{N F}\left(c_{G}^{j}+c_{\mathrm{Re}}^{j}+c_{U}^{j}+c_{I}^{j}+c_{D}^{j}+c_{L o}^{j}\right) \text { is total rail utilization }
$$

cost in the life cycle; $N F$ is the life cycle; $Q_{L e}$ is the service 
life of rail, the economic life determined by model; $Q_{L e}^{w}$ is the wear life of rail; the meaning of other parameters is same as before.

\section{ANALYSIS RESULTS OF THE MODEL}

According to the transportation condition of a certain line, determine the parameters of model, see Table $\mathbf{1}$.

In the analytic model of rail grinding parameters based on life-cycle cost, metal removal and grinding interval shall be so determined that a balance could be sought between wear and crack development. Importing the relationship of mental removing and grinding interval to the model can calculate the total rail utilization cost in the condition of different rail service life during the life cycle. Fig. (2) is the total present value of rail utilization cost in the condition of different rail service life (grinding interval is 26MGT, mental removal is $0.6 \mathrm{~mm}$ ).

Table 1. Model parameters.

\begin{tabular}{|l|c|}
\hline \multicolumn{1}{|c|}{ Type } & Value \\
\hline \hline Annual volume (MGT) & 130 \\
\hline Annual flaw detection time & 12 \\
\hline Flaw detection reliability & 0.45 \\
\hline The shape parameter of Weibull distribution & 1.952 \\
\hline The position parameter of Weibull distribution & 65.5 \\
\hline The characteristic parameter of Weibull distribution & 3423.9 \\
\hline Unit price of rail replacement(yuan/meter) & 2202 \\
\hline Unit price of flaw detection(yuan/meter/time) & 1.08 \\
\hline Unit price of emergency repair(yuan/time) & 460965 \\
\hline Unit price of derailment loss(yuan/time) & 5543500 \\
\hline Unit price of grinding(yuan/meter/time) & 3.7 \\
\hline Unit price of railway taking-up cost(yuan/hour) & 454350 \\
\hline Life cycle(year) & 50 \\
\hline Discount rate & $10 \%$ \\
\hline
\end{tabular}

As can be seen from the Fig.(2), with the improvement of rail service life, the total present value of rail utilization cost shows the tendency that it decreases firstly and then increases, and the cost-optimal rail service life is 928 MGT as observed at point A in Fig.(2). However, due to the restriction of limiting wear, the actual rail service life can not achieve this ideal time. In this case, the wear life is $628 \mathrm{MGT}$, shown as point B in Fig. (2). It seems that after rail grinding, improving the wear limit can increase the use economy of rail. This is the important reason why Canadian Pacific Railway Company increases the limiting wear by $36 \%$ after grinding [14].

In order to analyze the total present value of rail utilization cost at different rail grinding interval, firstly analyze the minimum total present value of rail utilization cost at one grinding interval, then compare the summarization of the minimum total present value of rail utilization cost at different rail grinding interval. Fig. (3) is the comparison diagram.

As can be seen from the Fig.(3), the total present value of rail utilization cost showed the tendency that it decreases firstly and then increases with the enlargement of grinding interval (grinding interval is increasing). In the cases of different grinding intervals, the total present value of rail utilization cost reaches the minimum when the grinding interval is 29 MGT. Therefore, the most economical grinding interval is $29 \mathrm{MGT}$, and the rail service life is $664 \mathrm{MGT}$. In consideration of the fact that wide grinding interval may bring about deep cracking and significant metal removal that require repeated grinding, which makes actual grinding operation more difficult; hence, the grinding interval shall be appropriately reduced from the base level; the identified economic grinding interval is $23 \mathrm{MGT} 26 \mathrm{MGT}$, the metal removal being $0.5 \mathrm{~mm} \sim 0.6 \mathrm{~mm}$; the economic service life of rail being $620 \mathrm{MGT} \sim 668 \mathrm{MGT}$.

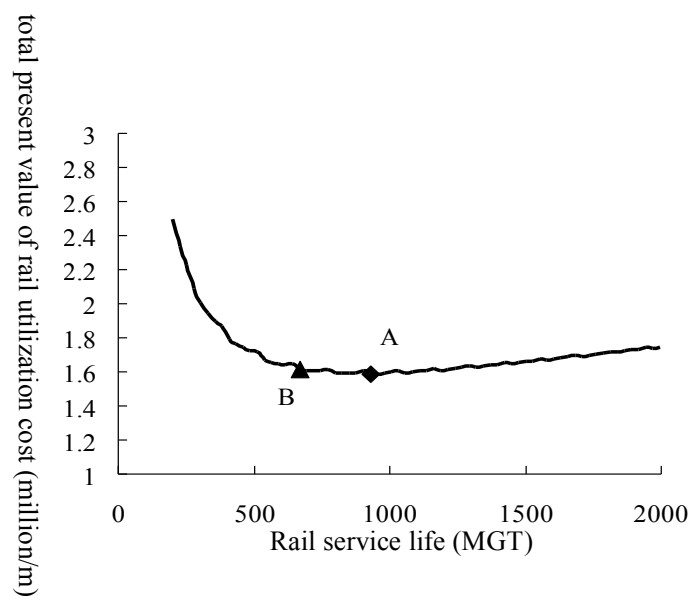

Fig. (2). The variation of total present value of rail utilization cost with different service life.

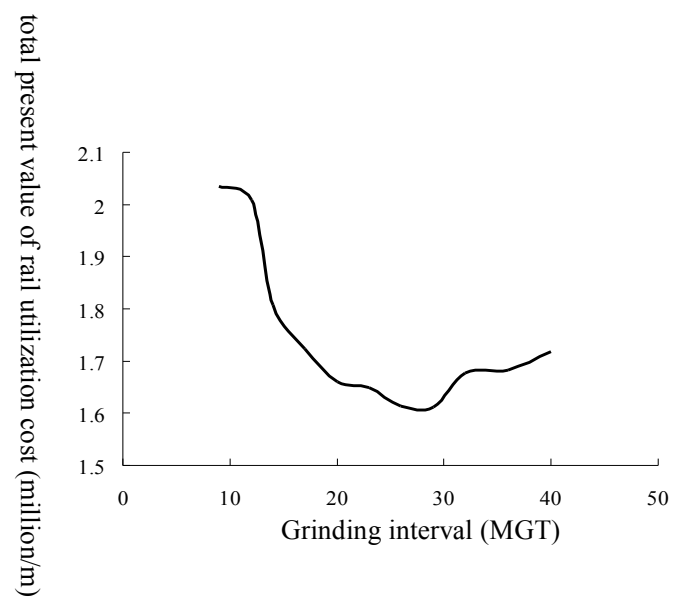

Fig. (3). Comparison of minimum total present value at different grinding interval. 


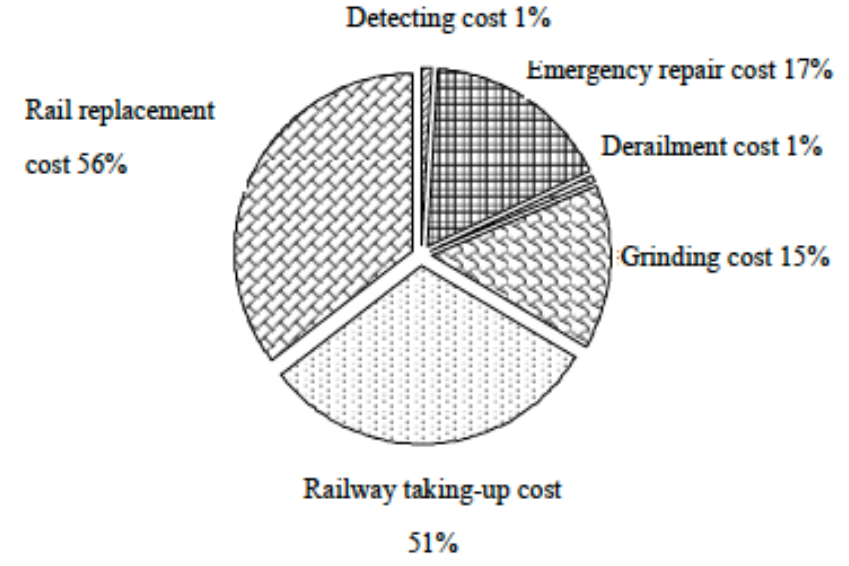

Fig. (4). Composition of total rail utilization cost.

The proportion of various fees to the total rail utilization cost at rail economical service life (grinding interval is 26 MGT) is shown in Fig. (4).

As can be seen from the Fig.(4), the cost of rail replacement is the maximum part, the cost of railway taking-up cost is in second place, and the cost of these two accounts for nearly $70 \%$ of the total cost. The grinding cost only accounts for $15 \%$ of the total cost. The statistics of the composition of total rail utilization cost at different grinding interval suggest that the cost of rail replacement and railway taking-up cost both are two of the largest. Therefore, to improve the economic benefit of rail utilization, it is necessary to reduce these two costs. Because the service life of rail is controlled by the rail limiting wear (rail grinding life), less than the rail economic service life, so we must improve wear life to improve the economy of rail utilization. On the one hand, rail's wear life can start with improving the limiting wear of rail, such as the Canadian Pacific Railway Company increased the wear limit by $36 \%$ after grinding [14]. On the other hand, reducing the grinding rate (which includes natural wear and rail grinding). If the best wear rate is reduced from $0.04 \mathrm{~mm}$ /MGT to $0.02 \mathrm{~mm} / \mathrm{MGT}$, wear life will be doubled. Meanwhile, the mental removal will reduce. Hence, the grinding rate and taking-up time could be improved to reduce grinding cost and railway taking-up cost, thereby considerably enhancing rail operation cost-effectiveness. Because the best grinding rate is controlled by the rate of crack propagation, reducing the crack initiation and propagation rate is the key to reduce the best grinding rate. Decarburized layer of surface can be eliminated by pre-grinding, and the appearance of rail breakage would be put off. So the new rail must be pre-grinded after being placed in track. Additionally, wheel and rail profiles shall be optimized by employing anti-fatigue rail profiles to reduce rail crack growth [15].

\section{CONCLUSION}

Based on life cycle cost management theory, this article has established the analytic model of rail grinding parameters based on life-cycle cost, taken numerical simulation analysis with actual line parameters and got the following conclusion:
(1) Under the determined grinding parameters, the total present value of rail utilization shows the tendency that it decreases firstly and then increases with the increase of rail service life, and the most economical rail service life is 928 MGT. However, due to the limit of rail wear life, the economic life of line can not be reached.

(2) The total present value of rail utilization cost shows the tendency that it decreases firstly and then increases. With the increase of grinding interval, there is an extreme point in the variation tendency

(3) In the economic cost of rail service life, rail replacement and waste of railway taking-up cost are two of the biggest contributors. Effective rail maintenance and repair methods can reduce the rail breakage, decrease the cost of these two parts, and improve the operation costeffectiveness.

\section{CONFLICT OF INTEREST}

The authors confirm that this article content has no conflict of interest.

\section{ACKNOWLEDGEMENTS}

This work was supported by National Natural Science Foundation of China (No.51208318, No.51208319), Hebei Provincial Natural Science Foundation of China (No. E2011210032), Key Project of Hebei Educational Committee of China (No. ZD2010110) and Key Laboratory of Road and Traffic Engineering of the Ministry of Education, Tongji University (No. 201102).

\section{REFERENCES}

[1] S. Wolfgang, "Rail grinding strategies for achieving optimum results: an inventory", Railway Eng. Int., pp. 4-6, 2008.

[2] J. Kalousek, E. Magel, "Managing rail resources", Bulletin 760Am. Railway Eng. Assoc., pp. 139-148, 1997.

[3] E. Magel, M. Roney, J. Kalousek, P. Sroba, "The Blending of Theory and Practice in Modern Rail Grinding", Fatigue Fract. Eng. Mat. Struct., vol. 26, pp. 921-929, 2003.

[4] W. Schoech, R. Heyder, H. Grohmann, "Contact Geometry and Surface Fatigue Guidelines for Appropriate Rail Maintenance”, in Proc. 7th Int. Conf. on contact mechanics and wear of rail/wheel systems (CM2006), Brisbane, Australia, 2006, pp. 23-29.

[5] X. S. Jin, X. Du, J. Guo, D.B. Cui, "State of Arts of Research on Rail Grinding", J. Southwest Jiaotong Uni., vol.45,pp1-11,2010.

[6] Q. Y. Zhou, C. H. Tian, Y. H. Zhang, "Research on Key Rail Grinding Technology of High-Speed Railway", China Railway Sci., vol. 33, pp. 66-70, 2012.

[7] Y. L. Huang, X. Y. Xu, Engineering Economics (second edition), Nanjing, 2006, pp.30-159.

[8] Y. L. Xue, "Maintenance cost analysis based on Life Cycle Cost", East China Elect. Power, vol.36, pp. 87-90, Oct.2008.

[9] J. X. Wang, M. S. Wang, "Research of Life Cycle Information Management System for Passenger Train Railway Based on GIS", J. Shijiazhuang Railway Inst., vol.19, pp. 110-112,116, Jan.2006.

[10] B. S. Yan, "Rail Mechanics and Rail Damage", Chengdu, 1989, pp. 20-210.

[11] B. L. Hou, Z. L. Xu, P. Y. Gong, "Damage Forecast of Active Rail", J.China Railway Soci., vol. 20, pp. 127-131, 1998.

[12] Railway Ministry of the People's Republic of China, Railway Maintenance Rules, Beijing, 2006, pp. 50-180. 
[13] A. M. Zarembski, P. E. Fasme, The art and science of rail grinding, Omaha, 2005, pp. 100-301.

[14] S. Peter, E. Magel, F. Prahl, "Getting the most from rail grinding", Railway Track Struct., vol.99, pp. 30-33, Dec. 2003.
[15] S. Wolfgang, "Rolling contact fatigue mitigation by grinding", in 7th International Conference on Contact Mechanics and Wear of Rail/Wheel Systems, Brisbane, Australia, 2006, pp. 201-212.

Received: May 26, 2015

Revised: July 14, 2015

Accepted: August 10, 2015

(C) Jianxi et al.; Licensee Bentham Open.

This is an open access articles licensed under the terms of the Creative Commons Attribution-Non-Commercial 4.0 International Public License (CC BY-NC 4.0) (https://creativecommons.org/licenses/by-nc/4.0/legalcode), which permits unrestricted, non-commercial use, distribution and reproduction in any medium, provided that the work is properly cited. 